\title{
5HTT is associated with the phenotype psychological flexibility: results from a randomized clinical trial
}

\author{
Andrew T. Gloster • Alexander L. Gerlach • Alfons Hamm • Michael Höfler • \\ Georg W. Alpers · Tilo Kircher · Andreas Ströhle · Thomas Lang • \\ Hans-Ulrich Wittchen · Jürgen Deckert • Andreas Reif
}

Received: 3 August 2014 / Accepted: 7 January 2015 / Published online: 15 January 2015

(C) Springer-Verlag Berlin Heidelberg 2015

\begin{abstract}
Adaption to changing environments is evolutionarily advantageous. Studies that link genetic and phenotypic expression of flexible adjustment to one's context are largely lacking. In this study, we tested the importance of psychological flexibility, or goal-related context sensitivity, in an interaction between psychotherapy outcome for panic disorder with agoraphobia (PD/ AG) and a genetic polymorphism. Given the established role of the 5HTT-LPR polymorphism in behavioral flexibility, we tested whether this polymorphism (short group vs. long group) impacted therapy response as a function of various endophenotypes (i.e., psychological flexibility, panic, agoraphobic avoidance, and anxiety sensitivity). Patients with PD/AG were recruited from a large multicenter randomized controlled clinical trial on cognitivebehavioral therapy. Pre- to post-treatment changes by
\end{abstract}

\section{A. T. Gloster $(\bowtie)$}

Division of Clinical Psychology and Epidemiology, Department of Psychology, University of Basel, Missionsstrasse 62A, 4055 Basel, Switzerland

e-mail: andrew.gloster@unibas.ch

A. T. Gloster · M. Höfler · H.-U. Wittchen

Institute for Clinical Psychology and Psychotherapy, Technische

Universität Dresden, Dresden, Germany

\section{A. L. Gerlach}

Department of Psychology, Clinical Psychology

and Psychotherapy, University of Cologne, Cologne, Germany

\section{A. Hamm}

Department of Clinical and Biological Psychology, Ernst MoritzArndt University of Greifswald, Greifswald, Germany

\section{G. W. Alpers}

Chair of Clinical Psychology, Biological Psychology and Psychotherapy, Department of Psychology, University

of Mannheim, Mannheim, Germany
5HTT polymorphism were analyzed. 5HTT polymorphism status differentiated pre- to post-treatment changes in the endophenotype psychological flexibility (effect size difference $d=0.4, p<0.05$ ), but none of the specific symptomrelated endophenotypes consistently for both the intentto-treat sample $(n=228)$ and the treatment completers $(n=194)$. Based on the consistency of these findings with existing theory on behavioral flexibility, the specificity of the results across phenotypes, and the consistency of results across analyses (i.e., completer and intent to treat), we conclude that 5HTT polymorphism and the endophenotype psychological flexibility are important variables for the treatment of PD/AG. The endophenotype psychological flexibility may help bridge genetic and psychological literatures. Despite the limitation of the post hoc nature of these analyses, further study is clearly warranted.

\section{T. Kircher}

Department of Psychiatry and Psychotherapy, University of Marburg, Marburg, Germany

A. Ströhle

Department of Psychiatry and Psychotherapy, Charité-

Universitätsmedizin, Berlin, Germany

T. Lang

Christoph-Dornier-Foundation for Clinical Psychology, Bremen,

Germany

J. Deckert · A. Reif

Department of Psychiatry, Psychosomatics and Psychotherapy,

Center of Mental Health, University of Würzburg, Würzburg,

Germany 
Keywords 5HTT · Psychological flexibility ·

Psychotherapy $\cdot$ Panic disorder $\cdot$ Agoraphobia $\cdot$ Evolution

\section{Introduction}

Organisms that flexibly adapt to continually changing contingencies have an evolutionary advantage over those organisms that cannot or do not readily adapt [1]. Stated simply, variation and selection guide evolutionary change. Although this principle is applicable and can help organize research across multiple analytical levels (i.e., genetic, epigenetic, behavioral, and symbolic [2]), it is seldom applied. In as much as evolutionary theory offers a unifying framework that helps to interpret findings across levels, the notoriously inconsistent associations between genetic structures and psychological constructs suggest a potential area for improvement. Indeed, evolutionarily informed interpretations of genetic data have begun to explain context-dependent genetic expression such that previously viewed contradictions begin to be resolved [3].

Parallel developments at the level of phenotype specification may also help elucidate evolutionarily informed genetic findings. For example, the construct of psychological flexibility (PF), defined as the process of contacting the present moment fully and nonjudgmentally and persisting or changing behavior in the service of chosen values [4], is hypothesized to have evolutionary implications [5]. Stated succinctly, PF describes one's ability to respond appropriately to situational demands (environmental and internal) for the good of their goals [6]. An example of an individual expressing high levels of PF would be someone who, despite past trauma and subjective rules about avoiding pain, can choose to remain psychologically present in a situation despite that pain and act in a way that is consistent with long-term values (e.g., social contact). Moreover, $\mathrm{PF}$ is a key element in healthy psychological functioning $[7,8]$ and is associated with Big Five personality traits in expected directions and magnitudes [9, 10]. Conversely, psychological inflexibility is associated with a host of indicators of psychopathology [4] and predicts unique variance not accounted for by other standard questionnaires [11]. PF is also an important determinant of psychotherapy response [12]. Indeed, meditational and laboratory studies suggest that $\mathrm{PF}$ is an active and salient mechanism of action in psychotherapy $[13,14]$. Taken together, PF appears important for therapeutic change-and via increased sensitivity to one's current context and long-term goals, perhaps change more broadly.

Studies on the neurobiological correlates and genetic associations of flexible behavior and change have focused primarily on the serotonergic system. The promoter polymorphism in the gene encoding the serotonin transporter
(5HTT) influences gene expression and is associated with anxious-depressive symptoms $[15,16]$ and, thus far, is the best-described candidate gene for such symptoms. Specifically, short alleles of this polymorphism (termed 5HTTLPR) are associated with an increased risk of depression, suicidality, and related phenotypes in the presence of adverse life events [17, 18].

However, if these alleles occasioned exclusively negative consequences, why do they remain within the population at such high rates in human and non-human primates alike? Recent data suggest that these "risk" alleles are also associated with better executive processing and improved goal-directed attention [19-21]. This led to the assumption that carriers of the short allele process some information more efficiently; in case of negative emotional content, this may lead to dysfunctional behavioral outcome, while otherwise might be associated with beneficial cognitive and also probably social functioning [3]. Therefore, the short allele may not be specific to risk, but rather relevant for flexibility or plasticity [22].

Consistent with this context-dependent interpretation, $\mathrm{PF}$ harnesses learning processes that aim to exact change in functioning per se. This is in contrast with other constructs and therapies that specifically target symptoms for elimination or reduction. Indeed, PF consistently predicted functioning in treatment-seeking samples above and beyond that of symptom measures $[9,11]$. Individuals high in PF demonstrate increased variation of behavior (vs. narrow behavior repertoires), greater context sensitivity to the effects (vs. rigid rule following), and selective retention of behaviors that work for the individual's chosen goals [23]. Thus, instead of concentrating on reducing symptoms, promoting PF in these patients should increase attentiveness for what works with respect to their chosen goals [24]. This may be particularly important in exposure-based treatment, where patients are exposed to anxiety-provoking stimuli. Previous analyses have shown that patients who could flexibly interact with the increased anxiety during exposure had better outcomes at the end of treatment [13]; those who could not were more likely to drop out [25].

Given the role of 5HTT-LPR as a potential modifier of $\mathrm{PF}$ and that psychotherapy is an intense period where fundamental readjustment (i.e., flexibility) is required, we hypothesized that short alleles of this polymorphism would be associated with a greater change in PF during psychotherapy and, given the observed specificity of previous analyses [9, 13], that this difference would be unique to PF. In order to test the specificity of these effects, we compared this to symptoms and constructs traditionally associated with this disorder (e.g., panic attacks, agoraphobic avoidance, and anxiety sensitivity). We analyzed these questions in a large clinical trial on panic disorder with agoraphobia (PD/AG). 


\section{Methods}

\section{Clinical study}

The mechanisms of change in cognitive-behavioral therapy (CBT) [MAC] multicenter (Aachen, Berlin-Adlershof, Berlin-Charité, Bremen, Dresden, Greifswald, Münster, Würzburg) psychotherapy study was a randomized controlled clinical trial of exposure-based CBT that also involved experimental add-on studies of fear circuit mechanisms in PD/AG [26, 27]. In total, $N=369$ patients of European origin, who met DSM-IV criteria for PD/AG, as assessed by the Composite International Diagnostic Interview (CAPI-WHO-CIDI; DIAX-CIDI version), were included in the study $(n=301$ in the active treatment and $n=68$ in the waitlist). Exclusion criteria included bipolar disorder, schizophrenia, mental retardation, and neurological and neurodegenerative disorders. The present study is a subsample of patients who received active treatment and provided genetic information $(n=228$ intent to treat; $n=194$ treatment completers). The waitlist was not examined, as we were only interested in within treatment change and previous studies showed that patients in the waitlist did not significantly change on these variables [27]. Most patients $(91.3 \%)$ had at least one comorbid disorder, and nearly half $(47 \%)$ had at least three comorbid disorders. The sample was predominantly female $(75 \%)$ and entirely of Caucasian ethnicity. See Table 1 for more details.

Following informed consent, patients were randomized to one of two active treatment groups that differed exclusively with respect to the presence $(\mathrm{T}+)$ or the absence $(\mathrm{T}-$ ) of the therapist during exposure in situ. The manualized psychotherapy was administered in 12 twice-weekly sessions. All patients were free of all psychopharmacological medication; patients on psychotropic medication at intake underwent a washout period of 4 weeks.

Treatment procedure is described in detail elsewhere [2628]. Briefly, sessions 1-3 addressed psychoeducation and a functional analysis of the presenting problem; sessions 4-5 provided the treatment rational for exposure and implemented interoceptive exposure exercises. Sessions 6-8 consisted of standardized in situ exposure exercises. Session 9 reviewed treatment progress and addressed anticipatory anxiety. Sessions 10-11 again consisted of in situ exposure, but now targeted the patients' two most significant feared situations. Session 12 repeated crucial exposure-related elements of the manual and included relapse prevention. Both treatment groups were shown to be effective with large effect sizes [27]. The study was approved by local ethic committees.

\section{Genotyping}

Venous blood was drawn and DNA was extracted using a standard desalting method. A functional SNP was determined within the 5HTT-LPR 1 allele with an A to $\mathrm{G}$ substitution (rs25531), designated $\mathrm{l}_{\mathrm{A}}$ and $\mathrm{l}_{\mathrm{G}}$, respectively [29]. The $1_{A}$ variant is linked to higher levels of 5HTT expression, while the rarer $l_{G}$ variant can be compared functionally with the low-expressing $\mathrm{s}$ allele. Hence, genetic studies likely benefit from including information of this variant together with the LPR. We hence simultaneously genotyped the 43-bp insertion/deletion 5HTT-LPR polymorphism in the regulatory region of the serotonin transporter gene with rs 25531 along a previously described protocol [30]. Based on the initial study by Lesch and associates [31] and the vast majority of follow-up studies, we assumed a dominant effect of the short allele (see also the review by [17] for a thoughtful discussion of this topic). Thus, we grouped our sample into (a) the short (S) group including carriers of at least one short allele (s) or at least one $\mathrm{l}_{\mathrm{G}}$-allele $(\mathrm{S}+\mathrm{LG})$ and (b) the long (L) group subjects homozygous for the $5 H T T$-LPR L variant also carrying the $\mathrm{A}$-allele of $\mathrm{rs} 25531$ (i.e., $\mathrm{l}_{\mathrm{A}} / \mathrm{l}_{\mathrm{A}}$ ). Genotypes were determined blind for phenotypes. Hardy-Weinberg criteria, assessed with DeFinetti (http://ihg.gsf.de/cgi-bin/hw/hwa1. $\mathrm{pl}$ ), were fulfilled for 5HTT-LPR genotype distribution in the present sample. Characteristics of the sample can be seen in Table 1.

\section{Assessment}

Acceptance and Action Questionnaire II (AAQ-II-10 item version; [32]) is a 10-item unidimensional self-report measure for PF. Items are rated on a seven-point-Likert-type scale, with scores ranging between 10 and 70 . Scores are poled so that higher scores reflect more PF. The AAQII explains unique variance in $\mathrm{PD} / \mathrm{AG}$ patients [11]; has excellent internal consistency and good test-retest reliability; and is sensitive to treatment effects [27].

Structured Interview Guide for the Hamilton Anxiety Scale (SIGH-A/HAM-A; [33]) is a 14-item interview commonly used to assess the severity of a broad range of anxiety symptoms. The SIGH-A has demonstrated high values of inter-rater and test-retest reliability and is commonly used in outcome studies.

Clinical Global Impression Scale-Severity Subscale (CGI; [34]. CGI is a clinician-rated scale that measures the overall severity of a disorder, with scores that range between 1 (no disorder) and 7 (among the most severely ill patients). The scale queries for information across the facets of psychopathological symptoms such as anxiety, avoidance, and overall functional level before making a global rating. Scores on the CGI are sensitive to change in panic treatment [27, 35].

Mobility Inventory (MI; [36]. Mobility Inventory (MI). The MI is a self-report questionnaire that measures the degree of agoraphobic avoidance across 27 situations, each of which is rated with respect to being in 
Table 1 Demographic and clinical characteristics by polymorphism

\begin{tabular}{|c|c|c|c|c|c|c|c|}
\hline \multirow{2}{*}{$\begin{array}{l}\text { Characteristic } \\
\text { Demographics }\end{array}$} & \multicolumn{6}{|c|}{ Mean (SD)/no. (\%) } & \multirow[t]{2}{*}{$p$ value } \\
\hline & \multicolumn{2}{|c|}{ Total $(n=228)$} & \multicolumn{2}{|c|}{ Short $(N=156)$} & \multicolumn{2}{|c|}{ Long $(N=72)$} & \\
\hline Age & 36.2 & 10.9 & 36.6 & 11.4 & 35.5 & 9.9 & 0.477 \\
\hline \multicolumn{8}{|l|}{ Sex } \\
\hline Male & 57 & 25.0 & 42 & 26.9 & 15 & 20.8 & \multirow[t]{2}{*}{0.403} \\
\hline Female & 171 & 75.0 & 114 & 73.1 & 57 & 79.2 & \\
\hline \multicolumn{8}{|l|}{ Years of education } \\
\hline 8 & 28 & 12.3 & 23 & 14.7 & 5 & 6.9 & \multirow[t]{4}{*}{0.700} \\
\hline 10 & 98 & 43.0 & 66 & 42.3 & 32 & 44.4 & \\
\hline $12-13+$ & 97 & 42.5 & 64 & 41.0 & 33 & 45.8 & \\
\hline No formal degree & 5 & 2.2 & 3 & 1.9 & 2 & 2.8 & \\
\hline \multicolumn{8}{|l|}{ Living arrangement } \\
\hline With parents & 9 & 4.0 & 5 & 3.2 & 4 & 5.6 & \multirow[t]{4}{*}{0.767} \\
\hline Alone & 48 & 21.1 & 35 & 22.4 & 13 & 18.1 & \\
\hline With partner & 158 & 69.3 & 108 & 69.2 & 50 & 69.4 & \\
\hline Other & 13 & 5.7 & 8 & 5.1 & 5 & 6.9 & \\
\hline \multicolumn{8}{|l|}{ Employment } \\
\hline University student & 8 & 3.5 & 5 & 3.2 & 3 & 4.2 & \multirow[t]{5}{*}{0.594} \\
\hline Job training & 54 & 23.7 & 36 & 23.1 & 18 & 25.0 & \\
\hline Employed & 138 & 60.5 & 93 & 59.6 & 45 & 62.5 & \\
\hline Unemployed & 27 & 11.8 & 21 & 13.5 & 6 & 8.3 & \\
\hline Other & 1 & 0.4 & 1 & 0.6 & 0 & 0.0 & \\
\hline \multicolumn{8}{|l|}{ Social class } \\
\hline Lowest & - & & - & & - & & \multirow[t]{5}{*}{0.896} \\
\hline Lower middle & 11 & 4.9 & 6 & 3.9 & 5 & 6.9 & \\
\hline Middle & 54 & 23.9 & 40 & 25.8 & 14 & 19.4 & \\
\hline Upper middle & 138 & 61.1 & 94 & 60.7 & 44 & 61.1 & \\
\hline Upper & 23 & 10.2 & 15 & 9.7 & 8 & 11.1 & \\
\hline \multicolumn{8}{|l|}{ Marital status } \\
\hline Married & 79 & 34.8 & 55 & 35.3 & 24 & 33.3 & \multirow[t]{3}{*}{0.158} \\
\hline Divorced/widowed/separated & 27 & 11.9 & 19 & 12.2 & 8 & 11.1 & \\
\hline Never married & 121 & 53.3 & 81 & 51.9 & 40 & 55.6 & \\
\hline \multicolumn{8}{|l|}{ Clinical } \\
\hline \multicolumn{8}{|l|}{ Comorbidity, 12-month diagnoses } \\
\hline Alcohol abuse & 12 & 5.3 & 6 & 3.9 & 6 & 8.3 & 0.496 \\
\hline Alcohol dependence & 1 & 0.4 & 1 & 0.6 & 0 & 0.0 & 0.218 \\
\hline Harmful use of alcohol & 88 & 38.6 & 56 & 35.9 & 32 & 44.4 & 0.802 \\
\hline Nicotine dependence & 64 & 28.1 & 43 & 27.6 & 21 & 29.2 & 0.707 \\
\hline Any substance use disorder & 69 & 30.3 & 46 & 29.5 & 23 & 31.9 & 0.487 \\
\hline Other anxiety $\mathrm{dx}$ (besides PD/AG) & 194 & 85.1 & 131 & 84.0 & 63 & 87.5 & 0.370 \\
\hline GAD & 46 & 20.2 & 34 & 21.8 & 12 & 16.7 & 0.915 \\
\hline Social phobia & 97 & 42.5 & 66 & 42.3 & 31 & 43.1 & 0.516 \\
\hline Any specific phobia & 158 & 69.3 & 106 & 68.0 & 52 & 72.2 & 0.550 \\
\hline OCD & 23 & 10.1 & 17 & 10.9 & 6 & 8.3 & 0.714 \\
\hline PTSD & 8 & 3.5 & 5 & 3.2 & 3 & 4.2 & 0.105 \\
\hline MDE/dysthymia & 97 & 42.5 & 72 & 46.2 & 25 & 34.7 & 0.850 \\
\hline Pain disorder & 78 & 34.2 & 54 & 34.6 & 24 & 33.3 & 0.824 \\
\hline Number of comorbid diagnoses & & & & & & & \\
\hline None & 20 & 8.8 & 14 & 9.0 & 6 & 8.3 & 0.890 \\
\hline
\end{tabular}


Table 1 continued

Post hoc comparisons based on ANOVA for dimensional outcomes, Chi-squared test for independence for categorical outcomes

\begin{tabular}{llllllll}
\hline Characteristic & \multicolumn{3}{l}{ Mean $(\mathrm{SD}) /$ no. $(\%)$} & \multicolumn{2}{c}{$p$ value } \\
\cline { 2 - 7 } & \multicolumn{2}{l}{ Total $(n=228)$} & Short $(N=156)$ & Long $(N=72)$ & \\
\hline $1-2$ & 101 & 44.3 & 66 & 42.3 & 35 & 48.6 & \\
$3-4$ & 77 & 33.8 & 54 & 34.6 & 23 & 31.9 & \\
$5+$ & 30 & 13.2 & 22 & 14.1 & 8 & 11.1 & \\
BMI $(N=213)$ & 24.2 & 4.3 & 24.3 & 4.6 & 24.1 & 3.6 & 0.711 \\
\hline
\end{tabular}

that situation alone or accompanied by another person. The mean scores of the alone subscale (range 1-5) are reported. Scores of the MI are highly reliable and sensitive to change [36, 37].

Anxiety Sensitivity Index (ASI; [38]) is a self-report instrument assessing anticipatory fear and sensitivity to anxiety symptoms. Sixteen items are rated on a five-pointLikert scale. Internal validity is good (Cronbach's alpha from 0.82 to 0.92 ; [39]. Studies have found the ASI to mediate treatment outcome in PD [40].

\section{Statistical analysis}

One-way ANOVA was used to assess the effects of genotype status ( $\mathrm{S}$ vs. $\mathrm{L}$ ) on change observed during treatment (i.e., difference score from pre-treatment to post-treatment) on psychological flexibility (AAQ-II). To examine the specificity of this effect, this was repeated for the diagnostic- and symptom-based measures: (i.e., HAM-A total, CGI, number of panic attacks, MI-Alone, anxiety sensitivity (ASI)). As our hypothesis predicted change exclusively in PF, we decided not to apply a correction for multiple testing for the five diagnostic and symptom measures in order to maximize detection of change in these comparison variables and thereby creating a more conservative testing of the hypothesis.

Preliminary analyses examined the two treatment variants $(\mathrm{T}+$ and $\mathrm{T}-$ ) for differences on pre-treatment-posttreatment outcomes. As no differences existed between the groups, they were collapsed for all other analyses consistent with previous publications [13].

Intent-to-treat analyses were run utilizing all patients from the subsample of patients that provided genotype information. For these analyses, the last observation was carried forward in case of dropouts. Consistent with practices of randomized controlled trials, completer analyses were also run including only those patients who completed the post-treatment assessment (following session 12). Running both analyses serves as a check against potential bias resulting from a self-selecting sample and thereby offers a test of the robustness of the results.

\section{Results}

The two genotype groups did not differ at baseline on any demographic variable or measured phenotype (see Table 1).

As can be seen in Table 2, the one-way ANOVA analysis for the intent-to-treat sample of change between pretreatment to post-treatment was significantly different for PF. Patients with in the $\mathrm{S}$ group had almost twice as much increase in PF during treatment as patients in the L group $(d=0.3)$.

In contrast, the one-way ANOVA analysis for the intent-to-treat sample indicated that the change from pretreatment to post-treatment was not significantly different between the $\mathrm{S}$ and the $\mathrm{L}$ group for any aspect of the diagnostic criteria (i.e., panic attacks, agoraphobic avoidance), general anxiety level (HAM-A), general functioning (CGI), or anxiety sensitivity (ASI).

These analyses were repeated using only treatment completers. The results were consistent with the intent-to-treat analysis for all variables. The effect size of the difference in increase in PF between the $\mathrm{S}$ and the $\mathrm{L}$ group was consistent and comparable in magnitude $(d=0.3)$, suggesting that treatment completers and those that did not complete treatment did not differ in this respect.

\section{Discussion}

This study demonstrated that genetic variation in the $5 H T T$ gene is associated with change in PF during exposurebased cognitive-behavioral treatment. Patients carrying a low-expressing allele had nearly twice the increase in PF than those with the long allele. The results were robust across analyses (intent to treat vs. completer) and specific for PF. That is, there was no evidence for an association between the polymorphism and change on any other construct related to the treatment of PD/AG including anxiety, number of panic attacks, agoraphobic avoidance, or anxiety sensitivity. Recent theorization suggests that the short allele of the 5HTT transporter is not generally advantageous or disadvantageous per se, but rather its effects depend on the context in which the individual is responding [3]. This 
Table 2 Pre-treatment to post-treatment change (effect sizes) as a function of the 5HTT polymorphism

\begin{tabular}{|c|c|c|c|c|c|c|c|c|c|c|c|c|c|c|}
\hline & \multicolumn{7}{|c|}{ Intent to treat $(N=228)$} & \multicolumn{7}{|c|}{ Completer $(N=194)$} \\
\hline & \multicolumn{2}{|c|}{ Short $(N=156)$} & \multicolumn{2}{|c|}{ Long $(N=72)$} & \multirow[t]{2}{*}{$F$} & \multirow[t]{2}{*}{$p$} & \multirow[t]{2}{*}{$d$} & \multicolumn{2}{|c|}{ Short $(N=132)$} & \multicolumn{2}{|c|}{ Long $(N=62)$} & \multirow[t]{2}{*}{$F$} & \multirow[t]{2}{*}{$p$} & \multirow[t]{2}{*}{$d$} \\
\hline & ES & $\mathrm{SD}$ & ES & SD & & & & ES & SD & ES & SD & & & \\
\hline Psych. flexibility & 0.7 & 0.9 & 0.4 & 0.8 & 6.2 & 0.013 & 0.4 & 0.8 & 0.9 & 0.5 & 0.8 & 5.9 & 0.016 & 0.4 \\
\hline HAM-A total & -2.1 & 1.5 & -2.0 & 1.4 & 0.5 & 0.460 & 0.1 & -2.3 & 1.4 & -2.2 & 1.3 & 0.1 & 0.755 & 0.1 \\
\hline CGI total & -2.4 & 1.7 & -2.4 & 1.7 & 0.0 & 0.924 & 0.0 & -2.6 & 1.6 & -2.6 & 1.5 & 0.0 & 0.983 & 0.0 \\
\hline Nr. panic attacks & -0.6 & 1.0 & -0.6 & 1.0 & 0.0 & 0.864 & 0.0 & -0.6 & 1.0 & -0.6 & 1.0 & 0.0 & 0.962 & 0.0 \\
\hline MI-alone subscale & -1.1 & 0.9 & -1.1 & 0.8 & 0.2 & 0.650 & 0.0 & -1.2 & 0.9 & -1.2 & 0.8 & 0.1 & 0.812 & 0.0 \\
\hline Anxiety sensitivity & -1.2 & 1.1 & -1.1 & 1.0 & 0.2 & 0.630 & 0.1 & -1.3 & 1.1 & -1.3 & 0.9 & 0.1 & 0.761 & 0.0 \\
\hline
\end{tabular}

Psych. Flexibility = psychological flexibility (Acceptance and Action Questionnaire II); HAM-A = Hamilton Anxiety Scales; CGI = Clinical global impression; MI-Alone = Mobility Inventory Alone Subscale; Anxiety Sensitivity = Anxiety Sensitivity Index; ES = effect size based on the calculation (post-baseline)/SD of the baseline; $d=$ Cohen's $\mathrm{d}$ of the difference between $\mathrm{S}$ and $\mathrm{L}$ groups

evolutionarily informed perspective is consistent with these data.

To our knowledge, only a few previous studies have examined the relation between the $5 H T T$ polymorphism and treatment outcome in different disorders. For example, the short allele has been associated with poorer outcome (defined as symptom intensity) in exposure-based treatment for posttraumatic stress disorder [41]. However, the opposite was the case in children with anxiety disorders undergoing CBT (outcome defined as the absence of anxiety symptoms; [42]. Two further studies did not find any significant effect: either with panic disorder [43] or with depression [44]. Again, these studies defined outcome in terms of symptom reduction. The present study was consistent with these studies that failed to find a significant effect insofar as outcome is defined as symptom reduction.

The present findings concentrating on PF as opposed to symptoms may help account for the seemingly inconsistent findings observed in previous therapy outcome studies. These results may also help interpret the contradictory literature examining the relation between 5HTT and other constructs. In other words, a tight link between endophenotypes that tap into functional learning processes and neurobiological processes is needed. We assume that PF is a construct with evolutionary implications (i.e., increased variation of behavior, greater context sensitivity to the effects, and selective retention of behaviors that work for an individual's chosen goals [23]), thereby offering a stronger link from phenotype to other levels of analysis and processes. Behavioral flexibility may propel rapid evolutionary change [45], and extant evidence suggests that this can be replicated across species. For example, our data well mirror the effect of 5HTT knockout in rodents on flexible adaptation to environmental changes [3]. Taken together, these factors may be more useful in bridging levels of analyses and allow for clearer integration into the larger literature of evolutionary relevant change.
Methodologically, the present study utilized a longitudinal approach as opposed to cross-sectional association analyses (i.e., only at post-treatment or cross-sectional population study). These data thus allow for the examination of change in the endophenotype expression following treatment. Such an approach is oriented toward an understanding of what is learned during the therapy and in turn how the polymorphism interacts with this learning process-in the present case over the course of an intensive 6-week therapy. This perspective is consistent with findings that morphological change can occur quite rapidly and may be directly related to flexibility [45].

There are several possible mechanisms how the short allele may be associated with increases in flexibility. PF has been linked to frontal cortical executive functions [46]. Considering recent data suggesting that the short allele of 5HTT-LPR is associated with better attention and working memory function [19, 21], it is conceivable that the short allele of 5HTT-LPR may lead to enhanced performance of the frontal cortex, at the trade-off of increased susceptibility and sensitivity to environmental adversity and associated negative emotionality.

These findings are important for several reasons. First, these data show that the association between genetic polymorphism and change in phenotype observed was specific for PF. This is consistent with a growing literature of PF and recent evolutionary interpretations of genetic findings. In particular, it is consistent with previous research showing that promotion of PF leads to better functioning partially independent of symptoms [9, 13]. To the extent that these findings are consistent and replicated, the linking of flexibility concepts across levels of analysis represents a potential integrated step forward for treatment and basic research. The endophenotype PF may map on to the functional importance of the 5HTT polymorphism better than constructs that purely capture diagnostic symptoms $[5,8,9$, 23]. Further studies should examine under what conditions 
and in interaction with which genotype PF is also influenced by other environmental factors. Our data suggesting that 5HTT-LPR short allele carriers benefit from a greater potential to increase $\mathrm{PF}$ might provide an explanation why this allele remains in the population and further adds to the notion that this polymorphism should rather be dubbed a plasticity variant [22] than a vulnerability variant [47].

This study is limited in several ways. First, these analyses are ad hoc in nature. Although the data within the research network was collected in order to facilitate analyses across levels (i.e., genes, questionnaires, etc.), they were not collected to specifically address the current hypothesis. Thus, appropriate caution should be used when interpreting the results. Second, the sample consisted of patients recruited and treated in a randomized controlled trial. While the tight methodological rigor facilitates analyses such as those in this paper, it is not clear whether these results would translate to other settings or treatments. Third, the usual caveats of candidate gene studies apply (i.e., low sample size, other variants in linkage disequilibrium underlie the association, etc.). Although we thus encourage caution until these results can be replicated, we believe that these preliminary data contribute to the unifying theoretical framework across coordinated levels of selection and proposes a phenotype that should be examined in future studies.

Acknowledgments We are grateful to all individuals who participated in this study. This work is part of the German multicenter trial "Mechanisms of Action in CBT (MAC)." The MAC study is funded by the German Federal Ministry of Education and Research (BMBF; Project No. 01GV0615) as part of the BMBF Psychotherapy Research Funding Initiative. The Principal Investigators (PI) of the centers with respective areas of responsibility in the MAC study are as follows: V. Arolt (Münster: Overall MAC Program Coordination), H.U. Wittchen (Dresden: Principal Investigator (PI) for the Randomized Clinical Trial and Manual Development), A. Hamm (Greifswald: PI for Psychophysiology), A.L. Gerlach (Münster: PI for Psychophysiology and Panic subtypes), A. Ströhle (Berlin: PI for Experimental Pharmacology), T. Kircher (Marburg: PI for functional neuroimaging), and J. Deckert (Würzburg: PI for Genetics). Additional site directors in the RTC component of the program are G.W. Alpers (Würzburg), T. Fydrich and L.Fehm (Berlin-Adlershof), and T. Lang (Bremen). The study was further supported by the DFG (SFB TRR 58 Z02 to JD and AR, C02 to JD, B06 to AR; DE357/4-1 to JD and AR; RTG 1256, to ARand JD). T. Töpner and C. Gagel are credited for excellent technical assistance.

Conflict of interest Drs. Gloster, Gerlach, Hamm, Höfler, Alpers, Kircher, Lang, Deckert \& Reif report no conflicts of interest. Dr. Ströhle received research funding from the German Federal Ministry of Education and Research, the European Commission (FP6) and Lundbeck, and speaker honoraria from AstraZeneca, Boehringer Ingelheim, Bristol-Myers Squibb, Eli Lilly \& Co, Lundbeck, Pfizer, Wyeth and UCB. He was a consultant for Actelion. Educational grants were given by the Stifterverband für die Deutsche Wissenschaft, the Berlin Brandenburgische Akademie der Wissenschaften, the Boehringer Ingelheim Fonds, the Eli Lilly International Foundation, Janssen-Cilag, Pfizer and Eli Lilly \& Co. Dr. Wittchen is or has been on advisory boards of Servier, Pfizer, and Lundbeck. He also has received via his university grant support by Novartis, Lundbeck and Pfizer. Travel compensation for scientific meetings was received from Servier, Pfizer, Lundbeck, and Novartis.

\section{References}

1. Darwin C (1859) On the origin of species. Oxford World's Classics, Oxford

2. Jablonka E, Lamb MJ (2005) Evolution in four dimensions: genetic, epigenetic, behavioral, and symbolic variation in the history of life. MIT Press, Cambridge

3. Homberg JR, Lesch KP (2011) Looking on the bright side of serotonin transporter gene variation. Biol Psychiatry 69:513-519

4. Hayes SC, Luoma JB, Bond FW, Masuda A, Lillis J (2006) Acceptance and commitment therapy: model, processes and outcomes. Behav Res Ther 44:1-25

5. Wilson DS, Hayes SC, Biglan A, Embry DD (2014) Evolving the future: toward a science od intentional change. Behav Brain Sci 37:395-416

6. Williams KE, Ciarrochi J, Heaven PCL (2012) Inflexible parents, inflexible kids: a 6-year longitudinal study of parenting style and the development of psychological flexibility in adolescents. J Youth Adolesc 41:1053-1066

7. Hayes SC, Strosahl KD, Wilson KG (2012) Acceptance and commitment therapy: the process and practice of mindful change. Guilford, New York

8. Kashdan TB, Rottenberg J (2010) Psychological flexibility as a fundamental aspect of health. Clin Psychol Rev 30:865-878

9. Gloster AT, Klotsche J, Chaker S, Hummel KV, Hoyer J (2011) Assessing psychological flexibility: What does it add above and beyond existing constructs? Psychol Assess 23:970-982

10. Latzman RD, Masuda A (2013) Examining mindfulness and psychological inflexibility within the framework of big five personality. Personal Individ Differ 55:129-134

11. Kämpfe C, Gloster AT, Wittchen HU, Helbig-Lang S, Lang T, Gerlach AL, Richter J, Alpers GW, Fehm L, Kircher T, Hamm AO, Ströhle A, Deckert J (2012) Experiential avoidance and anxiety sensitivity in patients with panic disorder and agoraphobia: Do both constructs measure the same? Int J Clin Health Psychol 12:5-22

12. Ruiz FJ (2012) Acceptance and commitment therapy versus traditional cognitive behavioral therapy: a systematic review and meta-analysis of current empirical evidence. Int J Psychol Psychol Therapy 12:333-357

13. Gloster AT, Klotsche J, Gerlach AL, Hamm A, Strohle A, Gauggel S, Kircher T, Alpers GW, Deckert J, Wittchen HU (2014) Timing matters: change depends on the stage of treatment in cognitive behavioral therapy for panic disorder with agoraphobia. J Consult Clin Psychol 82:141-153

14. Levin ME, Hildebrandt MJ, Lillis J, Hayes SC (2012) The impact of treatment components suggested by the psychological flexibility model: a meta-analysis of laboratory-based component studies. Behav Ther 43:741-756

15. Canli T, Lesch KP (2007) Long story short: the serotonin transporter in emotion regulation and social cognition. Nat Neurosci 10:1103-1109

16. Lesch KP, Waider J (2012) Serotonin in the modulation of neural plasticity and networks: implications for neurodevelopmental disorders. Neuron 76:175-191

17. Uher R, McGuffin P (2008) The moderation by the serotonin transporter gene of environmental adversity in the aetiology of mental illness: review and methodological analysis. Mol Psychiatry $13: 131-146$ 
18. Uher R, McGuffin P (2010) The moderation by the serotonin transporter gene of environmental adversity in the etiology of depression: 2009 update. Mol Psychiatry 15:18-22

19. Enge S, Fleischhauer M, Lesch KP, Reif A, Strobel A (2011) Serotonergic modulation in executive functioning: linking genetic variations to working memory performance. Neuropsychologia 49:3776-3785

20. Enge S, Fleischhauer M, Lesch KP, Strobel A (2011) On the role of serotonin and effort in voluntary attention: evidence of genetic variation in $n 1$ modulation. Behav Brain Res 216:122-128

21. Enge S, Fleischhauer M, Lesch KP, Reif A, Strobel A (2012) Variation in key genes of serotonin and norepinephrine function predicts gamma-band activity during goal-directed attention. Cereb Cortex 24:1195-1205

22. Belsky J, Jonassaint C, Pluess M, Stanton M, Brummett B, Williams R (2009) Vulnerability genes or plasticity genes? Mol Psychiatry $14: 746-754$

23. Hayes SC, Sanford BT (2014) Cooperation came first: evolution and human cognition. J Exp Anal Behav 101:112-129

24. Pauli P, Conzelmann A, Mucha RF, Weyers P, Baehne CG, Fallgatter AJ, Jacob CP, Lesch KP (2010) Affect-modulated startle reflex and dopamine d4 receptor gene variation. Psychophysiology 47:25-33

25. Gloster AT, Lang T, Georgi N, Wittchen HU (submitted) How patients decide to engage in exposure predicts attrition: the importance of willingness

26. Gloster AT, Wittchen HU, Einsle F, Hofler M, Lang T, HelbigLang S, Fydrich T, Fehm L, Hamm AO, Richter J, Alpers GW, Gerlach AL, Strohle A, Kircher T, Deckert J, Zwanzger P, Arolt V (2009) Mechanism of action in cbt (mac): methods of a multicenter randomized controlled trial in 369 patients with panic disorder and agoraphobia. Eur Arch Psychiatry Clin Neurosci 259(Suppl 2):S155-S166

27. Gloster AT, Wittchen HU, Einsle F, Lang T, Helbig-Lang S, Fydrich T, Fehm L, Hamm AO, Richter J, Alpers GW, Gerlach AL, Strohle A, Kircher T, Deckert J, Zwanzger P, Hofler M, Arolt V (2011) Psychological treatment for panic disorder with agoraphobia: a randomized controlled trial to examine the role of therapist-guided exposure in situ in cbt. J Consult Clin Psychol 79:406-420

28. Lang T, Helbig-Lang S, Westphal D, Gloster AT, Wittchen HU (2012) Expostitionsbasierte therapie der panikstörung mit agoraphobie. Ein behandlungsmanual. Hogrefe, Göttingen

29. Nakamura M, Ueno S, Sano A, Tanabe H (2000) The human serotonin transporter gene linked polymorphism (5-httlpr) shows ten novel allelic variants. Mol Psychiatry 5:32-38

30. Wendland JR, Martin BJ, Kruse MR, Lesch KP, Murphy DL (2006) Simultaneous genotyping of four functional loci of human slc6a4, with a reappraisal of 5-httlpr and rs25531. Mol Psychiatry 11:224-226

31. Lesch KP, Bengel D, Heils A, Sabol SZ, Greenberg BD, Petri S, Benjamin J, Müller CR, Hamer DH, Murphy DL (1996) Association of anxiety-related traits with a polymorphism in the serotonin transporter gene regulatory region. Science 274:1527-1531

32. Bond FW, Hayes SC, Baer RA, Carpenter KM, Guenole N, Orcutt HK, Waltz T, Zettle RD (2011) Preliminary psychometric properties of the acceptance and action questionnaire-ii: a revised measure of psychological inflexibility and experiential avoidance. Behav Ther 42:676-688
33. Shear MK, Vander Bilt J, Rucci P, Endicott J, Lydiard B, Otto MW, Pollack MH, Chandler L, Williams J, Ali A, Frank DM (2001) Reliability and validity of a structured interview guide for the Hamilton anxiety rating scale (sigh-a). Depress Anxiety 13:166-178

34. Guy W (1976) Ecdeu assessment manual for psychopharmacology. U.S. Department of Health, Education, and Welfare, Rockwille

35. Barlow DH, Gorman JM, Shear MK, Woods SW (2000) Cognitive-behavioral therapy, imipramine, or their combination for panic disorder: a randomized controlled trial. J Am Med Assoc 283:2529-2536

36. Chambless DL, Caputo GC, Jasin SE, Gracely EJ, Williams C (1985) The mobility inventory for agoraphobia. Behav Res Ther 23:35-44

37. Chambless DL, Sharpless BA, Rodriguez D, McCarthy KS, Milrod BL, Khalsa SR, Barber JP (2011) Psychometric properties of the mobility inventory for agoraphobia: convergent, discriminant, and criterion-related validity. Behav Ther 42:689-699

38. Reiss S, Peterson RA, Gursky DM, McNally RJ (1986) Anxiety sensitivity, anxiety frequency and the prediction of fearfulness. Behav Res Ther 24:1-8

39. Alpers GW, Pauli P (2001) Angstsensitivitäts-index. Julius-Maximilians Universität, Würzburg

40. Smits JA, Powers MB, Cho Y, Telch MJ (2004) Mechanism of change in cognitive-behavioral treatment of panic disorder: evidence for the fear of fear mediational hypothesis. J Consult Clin Psychol 72:646-652

41. Bryant RA, Felmingham KL, Falconer EM, Pe Benito L, Dobson-Stone C, Pierce KD, Schofield PR (2010) Preliminary evidence of the short allele of the serotonin transporter gene predicting poor response to cognitive behavior therapy in posttraumatic stress disorder. Biol Psychiatry 67:1217-1219

42. Eley TC, Hudson JL, Creswell C, Tropeano M, Lester KJ, Cooper P, Farmer A, Lewis CM, Lyneham HJ, Rapee RM, Uher R, Zavos HM, Collier DA (2012) Therapygenetics: the 5httlpr and response to psychological therapy. Mol Psychiatry 17:236-237

43. Lonsdorf TB, Ruck C, Bergstrom J, Andersson G, Ohman A, Lindefors N, Schalling M (2010) The comtval158met polymorphism is associated with symptom relief during exposure-based cognitive-behavioral treatment in panic disorder. BMC Psychiatry 10:99

44. Bockting CL, Mocking RJ, Lok A, Koeter MW, Schene AH (2013) Therapygenetics: The 5httlpr as a biomarker for response to psychological therapy? Mol Psychiatry 18:744-745

45. Losos JB, Schoener TW, Langerhans RB, Spiller DA (2006) Rapid temporal reversal in predator-driven natural selection. Science 314:1111

46. Whelan R, Schlund MW (2013) Reframing relational frame theory research: Gaining a new perspective through the application of novel behavioral and neurophysiological methods. In: Dymond S, Roche B (eds) Advances in relational frame theory: research and application. New Harbinger Publications, Oakland

47. Glenn AL (2011) The other allele: exploring the long allele of the serotonin transporter gene as a potential risk factor for psychopathy: a review of the parallels in findings. Neurosci Biobehav Rev 35:612-620 